\title{
Semblanza de Hernando Devis Echandía
}

\author{
Jaime Alberto Arrubla Paucar \\ Jaime Esteban Arrubla Devis
}

Recepción: 07/04/2018 • Aprobación:28/09/2018 • Publicación: 19/12/2018

\section{Las migraciones del siglo XIX}

Durante el siglo Xix sucede una gran migración hacia Colombia desde el lejano Oriente, ocasionada por los grandes conflictos que se presentaban en países como el Líbano. Los hermanos Dahaavis se encontraban en ese grupo de inmigrantes que llegaron en barco al Puerto de Barranquilla, buscando dónde radicarse para emprender una nueva vida. Al llegar al puerto, uno de ellos falleció y los otros se registraron en nuestro país abreviando un poco su apellido árabe, para hacerlo más sonoro y concretado simplemente en la expresión Devis. Isaac no permaneció en la costa Caribe y emprendió viaje hacia el interior del país, remontando el río Magdalena hasta llegar a Girardot. De allí se dirigió a Chaparral, Tolima, donde se asentó.

En la población del Chaparral instaló una tienda de abarrotes y conoció a una joven miembro de una de las familias tradicionales y prestantes de la población, doña Petronila Echandía, con quien contrae nupcias y conforman la familia Devis Echandía, en cuyo seno nace Hernando y varios de sus hermanos uterinos. Doña Petronila muere de parto, cuando Hernando contaba con siete años de edad. El padre hace maletas y se va a probar suerte en Bogotá, dejando a sus hijos menores al cuidado de sus tías.

\section{La formación profesional}

Cuando Hernando llega a la edad de ingresar a la Universidad, uno de los jefes familiares de la línea materna, el maestro Darío Echandía, consagrado como 
uno de los importantes jurisconsultos del país, influye para que su sobrino proceda a adelantar sus estudios de Derecho en la Universidad Nacional de Colombia, en la ciudad de Bogotá.

La universidad pública y ser hijo de inmigrantes marcan la forma de pensar en el joven universitario, quien se ve atraído por las ideas liberales y por un sentido social y democrático en su concepción de la sociedad de la época.

El 19 de abril de 1941 se gradúa de abogado en la Universidad Nacional y en 1943 aparecería su primera obra jurídica; pero no sería hasta cuatro años después cuando daría sus primeros plumazos en la materia a la cual luego dedicaría toda su vida, el Derecho Procesal. Y es que antes de eso había escrito sobre temas tan diversos como: Características esenciales del derecho civil moderno. Régimen de las aguas en derecho colombiano, y Gravámenes sobre la propiedad raíz, y otros textos variados de menor extensión. Esto nos dice que no fue un hombre de aquellos que caen en el peligro y la facilidad de la especialidad, de la fragmentación del conocimiento y del Derecho. Hernando Devis será ante todo un jurista de carácter universal en Derecho.

Efectivamente, no solo el Derecho Procesal fue objeto de preocupación y análisis para este gran jurista; sus estudios de Derecho Civil son prolijos y avanzados para su tiempo. La crítica que desde los años cincuenta le hace a los postulados liberales de la autonomía privada, en el Derecho de Obligaciones, que realiza desde la Universidad Nacional y que se publica también en la revista del Colegio de Abogados de Medellín, sigue plenamente vigente y es objeto de análisis y reflexión en nuestro medio.

\section{La consagración del jurista y escritor}

Perfilar a Hernando Devis Echandía en su amplia trayectoria, implica un ejercicio de múltiples proporciones, debido precisamente a la naturaleza polifacética de este especial personaje hispanoamericano del siglo Xx.

Comencemos por referirnos al jurista consagrado prácticamente desde el momento que egresa de la Universidad. Adelantábamos nuestros estudios 
de Derecho en la Universidad Pontificia Bolivariana de Medellín en los años setenta, cuando escuchamos la primera referencia al maestro Devis Echandía, en la cátedra de Teoría General del Proceso; el profesor de la materia se refirió al tratadista colombiano, posicionándolo a la altura de los grandes del Derecho Procesal en el mundo entero. Pronto comprendimos las razones de su dicho cuando advertimos la dimensión de su obra, su magnífico Tratado de derecho procesal civil, aparecido en la década del sesenta, el Compendio que habría de seguirle para hacerlo accesible al público universitario y muy especialmente sus Nociones generales del derecho procesal civil y su Teoría general de la prueba judicial; obras científicas, con una moderna dogmática procesal de "desnuda abstracción teórica" sin alusión a ningún sistema jurídico en particular, universales, que serían el referente para los desarrollos del Derecho Procesal en la segunda parte del siglo Xx., citadas y conocidas en todo el mundo hispanoamericano.

La influencia del distinguido maestro en el contexto nacional no era menor; desde la década del cincuenta se convirtió en el principal tratadista del renacer del Derecho Procesal en Colombia; su tratado marca la huida de una tendencia procedimentalista del proceso, que se encuadraba en el estudio exegético de las disposiciones del antiguo Código Judicial, hacia el verdadero y real procesalismo, edificado bajo los postulados de un estado social y democrático de derecho. Su escuela se concreta en el Código de 1971, en gran parte de su redacción, que influye considerablemente en una nueva concepción del Derecho Procesal colombiano y en los códigos que le siguen en el contexto latinoamericano, con un fundamento nomoárquico impecable que hoy en día no ha sido superado.

El Código de Procedimiento Civil Colombiano de 1971, que estuvo vigente hasta enero de 2016, y que muchos de sus principios y contenidos pasan en el Código General del Proceso, sin duda obra insigne del profesor Devis Echandía, con la participación de importantes colaboradores como lo fue el doctor Hernando Morales Molina, cumple con esta premisa que ya 
advertía el maestro desde sus publicaciones, y concretó en nuestro país el paso del procedimentalismo hacia un sistema de Derecho Procesal moderno, más humano y garantista.

Pero esta no fue su gran obra, es más, nos atreveríamos a decir que fue el más modesto de todos sus logros. Distinto al pensamiento de muchos, no fue más que el resultado de años inagotables de producción de conocimiento. Su real y verdadero aporte a nuestro país se manifestó en los auditorios nacionales e internacionales desde el podio donde compartía su sabiduría, por supuesto en sus libros, pero también en las aulas de clase de innumerables facultades de Derecho; bien se dijo en el Vigésimo Tercer Congreso de Derecho Procesal, 2002, organizado en su homenaje, Charry Rivas, Dagoberto. Universidad Externado de Colombia e Instituto Colombiano de Derecho Procesal: "El doctor Devis creaba derecho en sus clases".

\section{El Derecho Procesal, su forma de vida}

Su concepción sobre la razón de ser del proceso era definitiva y trascendente; ya advertía en la introducción de sus Nociones Generales, que:

Sabemos que no puede concebirse la existencia de una sociedad humana sin conflictos de intereses y de derechos, porque las normas jurídicas que la reglamentan son susceptibles, por naturaleza, de ser violadas y, algo más, esas violaciones son de ocurrencia casi necesaria y continua, dadas las limitaciones y supuestos los efectos propios de toda persona, que hacen imposible la idea de una vida de relación sin choques, sin querellas, sin disparidad de pretensiones y conceptos [...] De manera que ante tales hechos solo caben dos soluciones: $\mathrm{o}$ permitir que cada uno persiga su defensa y busque aplicar lo que entienda ser su justicia, personal y directamente, $o$ atribuir al Estado la facultad de dirimir tales controversias. De ahí la existencia del Derecho Procesal que, en cuanto su origen o causa primaria, responde a una necesidad, que es la de encausar, mediante la intervención del Estado, la acción de los asociados en el deseo de proteger sus intereses contra terceros y contra el mismo grupo... 
En la Revista Universitas, enero-diciembre de 2012, de la Universidad Javeriana, uno de los nietos del maestro Hernando Devis Echandía, coautor de esta crónica, Jaime Esteban Arrubla Devis, relataba en el discurso de la instalación de la Cátedra Hernando Devis Echandía:

Ya cursando la carrera de Derecho en la Universidad Javeriana, me encontré un día en medio de una gran y vieja biblioteca, plagada de innumerables e invaluables obras jurídicas, pero especialmente de la ciencia del Derecho Procesal. En esta me topé con una gran pila de hojas que apenas se encontraban unidas, no tenían pasta, ni portada, era un texto completamente desnudo y amorfo; este se encontraba repleto de tachones y notas al margen hechas, algunas con lápiz y otras en tinta, sobre lo que parecía un extenso articulado en hojas tamaño carta y en máquina de escribir. Parecía más que un libro, un ensayo hecho por un estudiante de primaria recién corregido por su profesor. Luego vi que como este había varios, todos de la misma extensión y edición. Eran copias casi idénticas, todos llenos de polvo y sus hojas expresaban la inequivocable imagen de aquellas que han sido manoseadas y rumiadas hasta el cansancio, como Biblia de abuela antioqueña. Esta era la biblioteca de Hernando Devis Echandía, los textos eran borradores de lo que aún hoy es nuestro Código de Procedimiento Civil, hechos en su antigua máquina de escribir con la que se encerraba horas, días y hasta semanas; había correcciones sobre correcciones, con la que sin lugar a dudas era su letra, que impregnaba de lado a lado, página a página, lo que evidentemente era el esfuerzo incansable por llevar su obra a la perfección. Ese era su código, de su puño y letra. Ese día tuve un íntimo encuentro con mi abuelo, con su trabajo, con su legado, con su amor por el Derecho y su pasión por el procedimiento.

Fue un jurista íntegro; sus obras iusprocesalistas, alrededor de 15 números, eran textos que giraban en la esfera del Derecho Procesal, siempre estaban impregnadas de filosofía, sociología, y un profundo entender de la ética y la moral, así como un gran sentido de lo práctico. Además, su obra está escrita con una claridad cristalina, con la simpleza de la genialidad y la elocuencia de la experiencia. 
Fue un hombre que dedicó su vida al Derecho Procesal, sí, pero esta empresa no la dirigió desde el dogmatismo, no como un fenómeno simplemente descriptivo, meramente positivo, no era un nomotecnista, como se diría en el citado Congreso celebrado en 2001. No, el maestro Devis abordó el Derecho Procesal desde el ser humano, del hombre, como aquel sujeto que se rinde ante la administración para encontrar justicia; no desde las normas, sino desde la persona. Su objetivo fue siempre el de humanizar el Derecho Procesal, de nutrirlo de principios y valores humanos, de acercar, en definitiva, a la justicia y al justiciable. Como diría el moralista francés, Luc de Clapiers, Marqués de Vauvenargues, ya en el siglo Xviii : "Solo se puede ser justo siendo humano". Esto, Hernando Devis lo entendía a la perfección. En uno de sus discursos leído para la clausura de las ceremonias de conmemoración del siglo de vigencia de la Ley Provisional de Organización Judicial Española, publicado en la Revista Pretor de España, 1970, y en Principios fundamentales de derecho procesal penal, 1981, y en Estudios de derecho procesal. T.I. de la Editorial ABC, Bogotá, en 1979, diría con gran acierto, en el aula máxima de la histórica Universidad de Salamanca:

La solución de los conflictos debe ser buscada y obtenida teniendo en cuenta la realidad humana étnica, social y geográfica de las decisiones respecto a los conflictos concretos entre pobres y ricos, poderosos y débiles, cultos e ignorantes, en forma que esas desigualdades reales no impidan una verdadera igualdad de oportunidades para obtener el fácil acceso a los tribunales, una verdadera oportunidad de buena defensa e iguales oportunidades prácticas para lograr así la verdadera justicia judicial en los casos concretos y la mayor humanización de ella.

Aun hoy, luego de los trabajos exhaustivos de tantos tratadistas, desde Wach hasta Devis, el Derecho Procesal parece propiedad exclusiva de unos pocos. Por ello aún persiste aquel erróneo creer entre algunos de que el Derecho Procesal es Derecho adjetivo, como mal lo describirían procesalistas de antaño, y así mismo, consagrados juristas en la actualidad ignoran la 
importancia sustantiva, aunque instrumental, del Derecho Procesal. Dando preponderancia al derecho sustantivo, porque lo demás, dicen, no es más que mero trámite. A ellos, Devis hoy diría con gran claridad:

"Si las normas sustanciales no están reglamentadas en forma eficaz y práctica en procedimientos procesales obligatorios, quedan convertidas en románticas y, en ocasiones, en mentirosas y engañadoras declaraciones políticas". Los estudiantes de Derecho debemos ser cautelosos, críticos, a la hora de acercarnos a esta riquísima disciplina, y esta obra es el vehículo ideal. Devis se ocupó, no del Derecho Procesal como un simple trámite, sino como medio eficaz para hacer valer el Derecho, y para ello este debía ser útil, práctico, por un lado, y justo, por el otro. Por ello se ocupó primordialmente del contenido del Derecho Procesal, de los principios; fue un abanderado de los principios en el entendido de que sin estos nunca podría haber verdadera justicia.

En el prólogo de la obra Nociones de derecho procesal civil, 2009, Jaime Guasp, eximio procesalista español, escribía:

No solamente para Colombia, donde de ese modo pasa a ocupar un relevantísimo puesto en la línea de los ordenamientos preocupados del Derecho Procesal, sino para todos los países, la obra actual de Hernando Devis Echandía es de una valía cuya ponderación favorable rebasa, por su volumen, los adjetivos habitualmente usados en ocasiones como esta. No nos damos cuenta, del todo, de hasta qué punto los conceptos generales, que habríamos de afinar y pulir diariamente, los dejamos enmohecer, no por el desuso, sino, al contrario, por su manejo diario, que no deja tiempo para cuidarnos de ellos ni nos damos cuenta de cómo semejante desatención pone en peligro la base misma de nuestra disciplina o de cualquier otra.

En nuestro país los principios están cayendo en desuso, no solo en nuestra disciplina sino en todas. De ahí la importancia de esta obra colosal, que debe mantenerse vigente en todas las épocas. Con la nueva colección literaria que lanzó hace algunos años la Facultad de Derecho de la Universidad 
Javeriana, denominada Clásicos jurídicos colombianos, inaugurada con la obra de Hernando Devis Echandía, se busca mantener vigente el pensamiento clásico, porque sí, como bien lo ha dicho el doctor Jairo Parra Quijano en tantas ocasiones, su obra es un Clásico del Derecho. Porque lo general es fundamental, y no podemos seguir cayendo en el error de la especialidad, en la que nos concentramos en un punto fijo y perdemos toda perspectiva. Hay que saber el contexto y desde dónde observamos, escribimos, leemos y, más importante, desde dónde se está enseñando. En esto mismo se fundamenta la creación de la Cátedra Hernando Devis Echandía, que busca impulsar el estudio, la investigación y difusión de un Derecho Procesal más humano, pero práctico, rico en principios, pero moderno.

Es pertinente citar al doctor Fernando de la Rúa, procesalista argentino, quien fuera su colega y amigo. En el prólogo que escribió, 2012, coedición de las editoriales Temis y de la Facultad de Ciencias, Pontificia Universidad Javeriana de Bogotá, para el relanzamiento del Compendio de Derecho Procesal, que muy acertadamente denominó Evocación, expresó:

En sus discursos y debates demostraba sus profundos conocimientos. Tenía una visión de alto vuelo jurídico, pero a la vez de hondo sentido práctico. No se dejaba enredar por las teorías, que dominaba, pero no olvidaba al hombre común que demanda justicia. Su activo ejercicio de la abogacía lo acercó siempre a la realidad del proceso, ése que no es una abstracción sino la obra de abogados y jueces en lo concreto, donde se ven las realidades de la vida.

En cuanto a la obra en particular, este jurista y expresidente de la República Argentina, en el mismo Compendio de Derecho Procesal, diría que:

"Al Código pudo llevar sus ideas principales, ya contenidas en sus libros: las relaciones entre acción y jurisdicción; las medidas para evitar la dilación del proceso; la conciliación; la intervención del juez en la formación de la litis y su rol en la producción y valoración de la prueba; la amplitud del recurso de casación. No fue un escritor apacible. Su creación se desenvuelve a grandes 
pasos. El abogado ejercitado en el pleito y autor de notables escritos defensivos, toma distancia para observar la realidad como jurista y describirla a la vez con el ritmo febril del litigante y la sabiduría del maestro.

Hay que decir que su obra jurídica sigue vigente y es de gran utilidad en la actualidad. Conceptos como la independencia judicial, la dicotomía entre oralidad y sistema escrito, las falencias de nuestro sistema judicial en su organización y su participación en la asignación del gasto público, la imperatividad o no del principio de doble instancia. También sus consideraciones respecto de la validez de la prueba ilícita. Todo ello pareciera escrito para nuestra realidad jurídica y política actual.

Como bien se dijo, no era un hombre que cayera en dogmas, buscaba la utilidad de la norma, en función del actor o del contradictor, no la teoría por la teoría. Bien decía, en un ensayo denominado La contribución de la sociología a la reforma de las leyes procesales, 1984, Editorial Comares de España, que "los principios teóricos que no obtienen una aplicación real y práctica en los casos concretos, solamente sirven como adornos florales para disimular las deficiencias e injusticias que en su aplicación se producen" y seguía: "Es importante, promulgar buenas normas, sustanciales y procesales, en las Constituciones y leyes, pero lo es más hacerlas realidad en la vida social e individual". Este es un gran choque de realidad que viven los estudiantes de esta profesión; luego de una primera mitad de carrera rica en teoría, principios, valores, e infinitas normas, se encuentran luego con la desilusión de lo que aparece, pero no es del todo; las primeras incursiones laborales, el consultorio jurídico, cuando dejan de conocer y empiezan a aprender verdaderamente, quisieran que todo funcionara como en la teoría.

\section{La visión de la oralidad en el proceso}

Su visión del Derecho Procesal siempre fue futurista, adelantada a su tiempo. En el año de 1970, ante el Congreso Iberoamericano realizado en Bogotá, Devis Echandía señala: 
Sin la menor duda, el proceso ideal debe ser oral; así habrá mayor concentración, verdadera inmediación, más celeridad, en general, mejor justicia; apenas se justifica mantener el escrito para la demanda y su respuesta. Pero para que el proceso oral marche bien y no fracase es indispensable aumentar el número de jueces (por el procedimiento oral, cada juez debe tramitar menos procesos que por escrito), dotar los despachos judiciales con mejores locales, suministrar grabadoras magnetofónicas y empleados que las manejen o en subsidio taquígrafos expertos, todo lo cual exige un aumento sustancial del presupuesto de gastos de la justicia que nuestro país, como prácticamente todos los latinoamericanos, no está en condiciones de soportar por ahora.

En la actualidad nos preguntamos si habremos superado los problemas que observaba el maestro Devis hace cuarenta años, para implementar la oralidad. Creemos que la realidad de lo que pasado con el sistema acusatorio nos brinda la respuesta.

Así, tanto en su obra Compendio, como en Nociones, y en Principios Fundamentales de derecho procesal penal, se refirió a la importancia de la oralidad, a esta como un "deber ser", pero también a su inconveniencia por su inaplicación en ese momento histórico, y es que ¿de qué valdría un sistema que no podría aplicarse? Sin embargo, en La contribución de la sociología jurídica a la reforma de las leyes procesales, 1984, diría en favor de la oralidad que

en el proceso oral la concentración e inmediación operan de manera perfecta, el juez adquiere una mayor capacidad para juzgar, en razón del conocimiento y apreciación directa que hace de las personas y hechos sometidos a su examen, dispone por último, de una mayor actividad y más amplias facultades. Todo esto permite un mayor predominio de los principios inquisitivos, de la inmediación y de la concentración, la celeridad y la economía procesal.

Abogó por un sistema mixto pero predominantemente oral, pues la superioridad de este sistema ayuda a impedir dilaciones y entorpecimientos del proceso; decía Séneca que: "Nada se parece tanto a la injusticia como la 
justicia tardía”, y ello sucede con el procedimiento escrito. Además, apuntó a la importancia aún más marcada de la oralidad en el proceso penal, como lo expresaría en la V versión de las Jornadas Latinoamericanas de Derecho Procesal, celebrada en Bogotá, en 1970, y en su obra Principios fundamentales de derecho procesal penal, y ello es hoy una realidad con la Ley 906. En La contribución de la sociología jurídica a la reforma de las leyes procesales, 1984, diría sobre la inmediación en el proceso penal que

es fundamental la mayor inmediación del juez con las partes, para en lo posible conocerlas, entenderlas y comprender el aspecto humano de su problema; menos arrogancia y distanciamiento del juez frente a las partes, para un trabajo en equipo, mejor como en una especie de mesa redonda que desde la altura intimidante de su tribuna.

\section{La defensa de la independencia judicial}

De igual manera enfatizó en un tema que hoy es de gran actualidad: La independencia judicial, un principio que se da por sentado, pero que en realidad de verdad se encuentra resquebrajado al interior de nuestro estado de derecho. En el Compendio de derecho procesal recalcó en la importancia de que los jueces, funcionarios

de tan delicada y alta misión puedan obrar libremente en cuanto a la apreciación del derecho y de la equidad, sin más obstáculos que las reglas que la Ley determine en cuanto a la forma de adelantar su conocimiento y proferir su decisión, que se refieren bien sea al procedimiento que han de seguir o a las pruebas que deben apreciar [...]. Un Estado en donde los jueces sufran la coacción de gobernantes o legisladores, deja de ser un Estado de Derecho.

Qué tan importante es este principio en los últimos tiempos en que la justicia se ha visto atacada por los demás poderes públicos; que desdicen de la labor que cumplen los jueces, que los acusan públicamente de actuar con criterios políticos. Qué mal mensaje a la sociedad cuando el Poder Ejecutivo 
no respeta la tarea que cumplen sus jueces; qué mal mensaje para los que estudian Derecho; que la sensación de que algo anda mal en el Poder Judicial. Qué difícil volver a rescatar la buena imagen de la justicia. Qué daño tan grande a una democracia.

La independencia del Poder Judicial la predicó y defendió hasta el cansancio. En homenaje al profesor uruguayo Eduardo J. Couture, en el que participara en 1977, advertía que la creación de jueces independientes, era precisamente una tutela que el Derecho Procesal brindaba a la persona humana. Advertía:

Justicia política es la negación de la verdadera justicia. La política corrompe cualquier sistema de justicia judicial, como un cáncer incurable que se esparce incontenible por todo el organismo; del prevaricato político al prevaricato por intereses patrimoniales solo hay un paso. Sin independencia verdadera del órgano jurisdiccional, no puede existir verdadera imparcialidad de sus funcionarios. Por eso estos principios fundamentales están entre los indiscutibles e indiscutidos del Derecho Procesal moderno.

La defensa de la independencia judicial será de allí en adelante su constante permanente. En la siguiente década pronunciaría en el Congreso de Derecho Procesal que se adelantaba en Medellín, un elocuente discurso crítico, en el que sostuvo que no puede hablarse de independencia judicial, si no se garantiza una participación mínima y decorosa en el presupuesto nacional y propone que esta se señale por reforma constitucional. La independencia judicial para el maestro comporta un salario justo para el juez, que le brinde el estatus social acorde a su misión; con salarios de miseria no hay la tranquilad psicológica para desempeñar la función judicial. La independencia se ve amenazada por los grupos delincuenciales y por la misma prensa hablada y escrita.

\section{Crítica a doble instancia}

Plenamente en boga el tema de la doble instancia a raíz de los juicios a los 
aforados por la Constitución de 1991, que juzga la Corte Suprema en única instancia, se viene señalando en el país que con este proceder se violan derechos fundamentales de los justiciables. En forma premonitoria el maestro Devis ya había abordado el tema relacionado con el principio de doble instancia; le asistía la razón cuando decía que existen mayores garantías en órganos judiciales plurales. Hoy, dentro del eterno juego político que termina llevándose consigo al ordenamiento, en la inescrupulosa manipulación de principios en favor de unos pocos, se ha pretendido universalizar el principio de doble instancia, una figura que la doctrina, aunque manteniéndola como principio, ha matizado, y así lo haría Devis, al señalar en su obra $L a$ contribución de la sociología jurídica a la reforma de las leyes procesales, 1984:

Estamos convencidos de que da más garantía una sola instancia ante tres magistrados, que constituyan salas de decisión dentro de tribunales seccionales, distribuidos en el país en circunscripciones territoriales mejor pequeñas que extensas, que dos instancias cuando la primera se tramita ante jueces unipersonales. Además, el sistema que proponemos terminará con la injusticia social que existe con la distribución jerárquica de competencias en razón de cuantías o valores de los litigios o los ilícitos penales, pues conduce a la creación de jueces inferiores de única instancia, de primera instancia y segunda instancia, unipersonales, y a tribunales plurales ante quienes solo llegan los asuntos de mayor valor o mayor gravedad, lo cual es antidemocrático e injusto, porque conduce a que los mejores magistrados conozcan (por regla general) de los asuntos de los litigantes ricos y de los delincuentes cuyo delito sea de los más graves dejándose para la inmensa mayoría de justiciables a los jueces de menor calidad.

\section{La justicia social}

Siempre fue enfático en la importancia de que la política estatal pusiera sus esfuerzos en mejorar la justicia judicial. Diría en su ya citado ensayo sobre sociología jurídica y la reforma de las leyes procesales que 
sin dotar a los jueces y magistrados de buenas remuneraciones y adecuada dignidad social dentro de la organización del Estado, paralela a la de los órganos Legislativo y Ejecutivo, no se conseguirán muchos juristas que estén dispuestos a consagrar sus vidas o parte de ellas, al apostolado y el sacrificio de administrar justicia judicial.

Y es que la carrera judicial debería ser el más honorable de los caminos, un sendero reservado para los mejores, los más consagrados, los mejor preparados, y no simplemente una opción residual de trabajo, debería ser una prioridad en la carrera de todo jurista. Porque allí podemos contribuir a la evolución y la dinámica de nuestra ciencia, y como se mencionó anteriormente, hacer un derecho funcional, útil, y no solo un conjunto de normas muertas, inertes. Diría el maestro, en la misma obra, que:

La Justicia Judicial no puede darle al país la Justicia Social que sus legisladores y gobernante le nieguen; pero sí puede hacer realidad la que estos consagren en normas abstractas e inclusive mitigar las injusticias sociales contenidas en las legislaciones locales mediante una interpretación dinámica y conforme al momento histórico presente, de las normas constitucionales, legales y reglamentarias; porque los jueces no pueden desconocer ni sustituir el derecho positivo impuesto por loslegisladores, pero sí pueden interpretarlo dinámicamente para hacerlo evolucionar y producir los efectos más conformes con la justicia social a través de sus sentencias, ya que la jurisprudencia debe estar siempre en evolución creadora de acuerdo con la evolución inevitable de la realidad social, económica, política, cultural, etc., a efecto de humanizar en cuanto sea posible las frías normas sustanciales y los rígidos mecanismos judiciales.

Vemos cómo a su vez hizo una ardua crítica al capitalismo como corriente económica que mueve la administración de justicia y su organización, que deja la justicia más aceitada para resolver los litigios de aquellos que controlan grandes masas de capital. No fue precisamente al lado del capital que reflexionaba el maestro Devis, los desamparados y necesitados de justicia siempre fueron su fin predilecto. 


\section{Una vida dedicada al Derecho y a la justicia}

$\mathrm{Su}$ personalidad fue envolvente $\mathrm{y}$ avasalladora, jurista enamorado del litigio como el que más, nunca permitió poner en juego su independencia profesional y académica. Cuentan que alguna vez dos distinguidos políticos de la capital lo visitaron para proponerle sellar un pacto entre intelectuales con el fin de defender propósitos comunes, loables por supuesto; con respeto, pero con decisión, les dijo que no podía comprometerse en agrupación alguna, que pudiera implicarle sacrificar su independencia de pensamiento y acción. Y así fue, y la mantuvo al punto de poder ostentar la independencia moral que un día lo llevó incluso a denunciar penalmente a la Sala Civil de Corte Suprema, por no haber invalidado un proceso, en el que con fraude, despojaban a una menor, habida extramatrimonialmente, de la herencia de su padre; los herederos, ante la imposibilidad de transar sobre el estado civil, negociaron, para que se tramitara el proceso y no se llevaran pruebas, a fin de que el resultado les fuera favorable. Al presidente de la República que lo buscó en apoyo para su reciente Estatuto de Seguridad, le tuvo que contestar que se había equivocado y que se disponía precisamente a hacer todo lo contrario.

Intelectual de rigor estricto y a veces hasta exagerado en sus dictámenes; de una extremada capacidad de trabajo. Cuentan que cuando presidía la Comisión Redactora del Código de Procedimiento, y llegaba a las reuniones, ya tenía los textos redactados para consideración de los comisionados y ya los había discutido con el profesor Hernando Morales.

La justicia siempre fue su fin predilecto, su vida fue un constante ir y venir en pos de ella. En su intervención atrás citada, como orador central en el aula máxima de la de Universidad de Salamanca, al cumplirse el centenario de la Ley Orgánica de la Justicia Española, en 1970, advertía en el siguiente párrafo, ese fervor que solo los devotos profesan a su divinidad:

Siguiendo este camino, España e Iberoamérica pueden mirar con optimismo el futuro de su justicia, que lo es a un mismo tiempo el de sus pueblos, y lograr que estos la conciban, no como una diosa implacable a la que deben temer, sino 
como una figura humana, pero pura; hermosa, pero inmancillable; estricta, pero acogedora; al alcance de todos, pero fiel a cada uno; necesaria e ineludible, pero a la cual se debe amar y respetar; para que cuando haya necesidad de acudir a someterse a ella, esto se haga con confianza y buena voluntad, de manera que sus decisiones se acaten con fe en su sabiduría, en su imparcialidad y en su rectitud.

Qué importante sería para Colombia que nuestro pueblo se acercara así fuera en una mínima parte, a este sueño de justicia, que tuvo el gran maestro desde la lejanía, en ese santuario de la cultura, como se refirió a nuestra dorada Salamanca.

El destino nos llevó a compartir con él los años dorados de su vida, lleno de anécdotas y profesando una devoción absoluta por el Derecho. Convencido en su plenitud de que el proceso era el mecanismo de máxima tutela de los derechos fundamentales, fue la última intervención que le escuchamos, debatida entre su gran intelecto y su enorme congoja debido a su drama familiar, circunstancia que terminó por minar la existencia de un roble del Derecho Procesal y de la democracia colombiana.

$\mathrm{Su}$ argumentación era impecable. No estaban en duda las grandes bondades de la acción de tutela, como instrumento de amparo de los derechos fundamentales y la gran revolución que ha propiciado para acercar la justicia al ciudadano. Pero no puede olvidarse que la acción de tutela se encauza en el país gracias a la labor que realizan principalmente todos los jueces que componen la justicia ordinaria. Pero tampoco cabe duda que tratándose de tutela contra sentencias y decisiones de órgano límite, el tema pone a temblar en el filo del cuchillo el principio de autonomía del Poder Judicial que tanto defendió el maestro.

El proceso es la máxima garantía para la tutela de los derechos fundamentales, señalaba el maestro Devis Echandía; si no está cumpliendo su función, debe cambiarse el proceso, volverse permeable al examen de constitucionalidad, pero de ninguna manera puede tolerarse que se imponga un tercero para que realice el examen constitucional por encima del proceso, 
afectando gravemente el sentido de especialidad; ello equivaldría a socavar la competencia del juez y restarle autonomía a la decisión judicial.

Mientras más demoremos en asumir la conciencia constitucional e involucrarla al proceso, será mayor el espacio cedido de la competencia de los jueces, en aras de la incursión extraña en la actividad procesal.

A buena hora este espacio en esta cátedra universitaria de su amada Tolima, que honra la memoria de quien fue grande en su patria y la hizo grande en el contexto hispanoamericano. Su entrañable Instituto de Derecho Procesal ha sido la más prolífera de sus obras, continuado y engrandecido a buena hora por su discípulo amado, es ahora el faro de las grandes reflexiones hispanoamericanas sobre la ciencia del Derecho Procesal; sin embargo, cuando le preguntaban al maestro Devis Echandía sobre su obra, con sentimiento y orgullo decía que no eran sus tratados y sus escritos sobre el Derecho Procesal, que simplemente, su mejor obra, eran sus adoradas hijas.

Estamos recordando, no a un maestro desaparecido, sino a un académico que sigue vivo entre nosotros. La historia del Derecho Procesal hispanoamericano apenas comienza con Hernando Devis Echandía. La cátedra que, con acierto instaló la Universidad Javeriana, con el apoyo y entusiasmo de su ilustre decano, el doctor Carlos Ignacio Jaramillo, que llevara su nombre, es una de las maneras que deben replicarse para mantener vivo su legado. No se trata de recordar y admirar su obra, sino de reflexionarla en sus múltiples contenidos y proyectarla al futuro; la gran riqueza en principialística con que dogmatizaba su ciencia, esta apenas por desarrollarse. Ese es su legado para las nuevas generaciones.

Para cerrar, citamos nuevamente el prólogo de Jaime Guasp, en Nociones Generales de Derecho Procesal Civil, 2009, que decía:

Es admirable la extensión de su obra. Para quien como él vivía las urgencias de su tiempo, cabe interrogarse cómo lo hizo, cuándo reunió la infinita paciencia de esa producción asombrosa que si bien tiene los rápidos trazos de su estilo no carece de la profundidad del estudio. Hay en ella un manejo preciso de los conceptos y del método. 
Y, en palabras escritas en la Revista de Derecho Procesal, de Panamá, país que también le debe su legislación procesal, en 2001, año de su muerte, "queda, a las generaciones presentes y a las venideras, continuar el camino marcado por este hombre extraordinario que pasó entre nosotros como un sencillo iluminador de sendas [...] La muerte no es verdad cuando se ha cumplido con la obra de la vida" (XXIII Congreso Colombiano de Derecho Procesal, Dagoberto Oharry Rivas, 2002). 